\title{
Pengelolaan Pertunjukan Teater di Jakarta Tahun 1972 Hingga Tahun 2017
}

\author{
Deden Haerudin ${ }^{1}$ \\ Program Studi Pendidikan Tari, Fakultas Bahasa dan Seni, \\ Universitas Negeri Jakarta
}

\begin{abstract}
Theater Performance Management in Jakarta from 1972 to 2017. Theatre performances are defined as communicating the ideas and thoughts of an artist through performances. Even though several power limitations limit the communication process. This study aims to determine theatre performances at the Jakarta Theater Festival from 1972 to 2017. This research was conducted by using the method of the historical case study. The research data was collected through documents and interviews and then categorized and analyzed to find several findings. The research findings are then validated by the data source of the triangulation validation technique, which synchronizes several data sources on the research findings. This research reveals that the management of theatre performances of FTJ adapting government policies which are authorized is marked by two periods (1972-2000 period and 2000-2017 period) by taking into account the needs and potentials of the artists' expressive power. FTJ has become a magnet for theatre activists to recognize as a theatre group, although few theatre groups disbanded after participating at FTJ. This study recommends further research topics to reveal post-participation theatre management at FTJ.

Keywords: arts centre in Jakarta; theatre festival; historical study; posttheatre management
\end{abstract}

\section{Pendahuluan}

Sentra kesenian seyogianya mewadahi para seniman untuk berkarya dan memberikan pengalaman yang berbeda bagi penikmat seni (Kevin \& Huwae, 2019). Karya-karya para seniman tersebut diuji sekaligus disosialisasikan melalui sejumlah kegiatan, antara lain pameran, pagelaran, dan pertunjukan, sehingga sentra kesenian dapat secara optimal menjadi pusat kegiatan para seniman, kritikus seni, dan penikmat seni.

Salah satu sentra kesenian yang senantiasa aktif dalam melaksanakan deretan kegiatan seni di DKI Jakarta ialah Taman Ismail Marjuki. Taman Ismail Marzuki (TIM) berlokasi di pusat Jakarta, yakni di Jalan Cikini Raya No. 73. TIM memiliki kegiatan rutin berupa sederet acara seni dan budaya, seperti pementasan drama, tari, wayang, musik, pembacaan puisi, pameran lukisan, dan pertunjukan film. Adapun acara-acara yang diselenggarakan di TIM beragam, baik acara bersifat tradisional maupun kontemporer, mulai dari yang bersifat tradisi asli Indonesia hingga mancanegara.

Khusus pada pertunjukan teater, TIM memiliki acara rutin, yakni berupa kompetisi teater yang dinamakan Festival Teater Jakarta (FTJ). Festival tersebut merupakan agenda acara tahunan di Indonesia. FTJ melibatkan sejumlah kelompok seniman teater untuk saling meningkatkan kemampuan kelompoknya dalam melaksanakan proses kreatif yang diwujudkan dalam sebuah karya pertunjukan. FTJ sebagai sebuah acara tertua di Indonesia, tentunya memiliki

1 Alamat korespondensi: Jl. R. Mangun Muka Raya No.11, RW.14, Rawamangun, Kec. Pulo Gadung, Jakarta Timur, DKI Jakarta 13220. Email: deden.rengga@gmail.com; HP.: 081287116554. 
sistem pengelolaan tertentu sehingga mampu melaksanakan kegiatan rutin sejak pertama kali diselenggarakan, yakni pada tahun 1972 hingga kini. Sistem pengelolaan FTJ disinyalir menjadi contoh pengelolaan acara serupa di kota-kota besar lainnya di seluruh Indonesia.

Namun, FTJ ini dinilai sebagai salah satu pengekangan kebebasan berkarya para seniman. Para seniman dalam FTJ dipaksa untuk memenuhi standar pertunjukan yang diputuskan oleh sejumlah orang yang tergabung dalam Dewan Kesenian Jakarta. Selain itu, kemasan FTJ dalam bentuk festival lebih dirasakan seperti halnya perlombaan yang secara bertingkat. Sejatinya sebuah karya memiliki daya ungkap tersendiri yang menunjukkan kedewasaan para senimannya. Oleh karena itu, penelitan ini bermaksud untuk mengetahui seluk-beluk pengelolaan pertunjukan dalam program kegiatan FTJ di pusat kesenian Jakarta. Adapun penelitian ini mengungkap kesejarahan Taman Ismail Marzuki sebagai pusat kesenian di Jakarta, kelembagaan dan sistem pengelolaan dewan kesenian Jakarta, serta sistem pengelolaan FTJ dan capaian yang berhasil diraih oleh FTJ.

Guna menjawab tujuan penelitian ini, peneliti menggunakan metode studi kesejarahan organisasi (Moleong, 2008; Stake, 2010). Penelitian ini dilaksanakan dengan kurun waktu 45 tahun, ditandai dengan awal penyelenggaraan FTJ hingga tahun 2017. Data pada penelitian ini antara lain sejumlah dokumen yang berkaitan dengan penyelenggaraan FTJ, wawancara kepada narasumber dari Dewan Kesenian Jakarta, beberapa juri FTJ, pengamat teater, pelaku seni serta penikmat teater, dan anotasi pengamat teater terhadap pelaksanaan FTJ.

Data penelitian tersebut dikelompokkan ke dalam kategori sejarah kelembagaan, kebijakan, dan proses penyelenggaraan FTJ. Kategori data sejarah kelembagaan dan kebijakan FTJ didapat dari dokumen internal milik Dewan Kesenian Jakarta. Sementara kategori proses penyelenggaraan FTJ didapat dari wawancara sejumlah Juri FTJ, pengamat, pelaku serta penikmat teater, dan komentar pengamat teater yang dituliskan pada sejumlah media cetak.

Setelah dikelompokkan dalam sejumlah kategori yang dipaparkan di atas, dilakukan analisis data untuk mencari generalisasi atas sejumlah temuan yang ada. Temuan tersebut kemudian divalidasi dengan menggunakan teknik triangulasi sumber data.

Teknik triangulasi sumber data merupakan kombinasi penguji keabsahan yang menguji sebuah temuan dari sumber data yang beragam. Dengan demikian, semua temuan yang dilaksanakan dan diungkapkan dapat dinyatakan sebagai temuan yang valid dan dapat dipertanggungjawabkan. Selanjutnya, keseluruhan temuan dirajut guna menghasilkan sebuah simpulan dari tujuan penelitian.

\section{Pembahasan}

Penelitian pengelolaan ini mengungkap adanya peran serta masing-masing elemen yang akan dipaparkan dalam sejumlah subkategori, antara lain sejarah perkembangan Taman Ismail Marzuki, kebijakan Dewan Kesenian Jakarta, dan Proses penyelenggaraan Festival Teater Jakarta tahun 1972-2000 dan proses penyelenggaraan Festival Teater Jakarta tahun 2000-2017.

\section{Sejarah Perkembangan Taman Ismail Marzuki}

Pendirian Taman Ismail Marzuki (TIM) bertujuan mengurangi gejolak sosial yang telah terjadi sejak tahun 1950. Sejumlah seniman saat itu sebagian besar dicap sebagai pro terhadap aktivitas Partai Komunis Indonesia (PKI).

Mencoba untuk tidak melupakan sejarah, pada 17 Agustus 1950, Lembaga Kebudayaan Rakyat (Lekra) resmi didirikan oleh PKI untuk mewadahi kalangan seniman (Ahmadi, 2020). Pada tahun 1965, para seniman anggota Lekra dieksekusi tanpa ampun (Probo, 2015). 
Beberapa pegiat seni Lekra yang bertahan memilih menerima kenyataan dan berdamai dengan pemerintahan yang baru dengan bersembunyi.

Sekuat apapun tekanan kekuasaan, karya-karya, gagasan, ataupun pemikiran seniman tetap hadir. Para seniman tetap saja menyuarakan aspirasi ataupun kegelisahan dirinya atas fenomena yang terjadi, baik di lingkungan sekitar maupun negara, dalam bentuk karya. Gejolak pemikiran yang datang dari kalangan seniman inilah yang mendesak pemerintah untuk menyediakan pusat kesenian. Oleh karena itu, TIM merupakan pusat kesenian Jakarta yang didirikan pada tahun 1968 atas kesepakatan sejumlah akademisi dan budayawan dengan Gubernur DKI Jakarta pada saat itu, Ali Sadikin.

TIM didirikan sebagai ruang ekspresi seniman yang menyajikan karya inovatif sekaligus wadah kontrol pemerintah atas gejolak yang mungkin dihadapi di kemudian hari. TIM membuka kebebasan seluasluasnya bagi para seniman untuk melakukan eksperimen terhadap ide-ide yang muncul dari ruang berpikir para seniman. Kebebasan tersebut dimaksudkan untuk menciptakan kreasi seni yang berkualitas.

Penetapan TIM sebagai wadah ekspresi mendorong sejumlah seniman Indonesia berkiblat ke DKI Jakarta serta memberikan tawaran pertunjukan ekperimen baru di atas pentas. Misalnya, Rendra dengan sederet nomor pertunjukannya, antara lain Be Bop, Ssssttt, Oedipus Rex, Menunggu Godot, Hamlet, dan nomor-nomor lainnya. Secara tidak langsung, TIM menyerap sejumlah seniman Indonesia untuk melakukan pentas di Jakarta. Ditambah dengan dukungan Jakarta sebagai pusat pemerintahan negara Indonesia, kaum seniman pun melakukan urbanisasi dan membentuk klaster urban dengan polemik yang dibawanya masing-masing. Hal demikian membuat TIM semakin padat dengan beragam kreativitias seniman dari seluruh daerah.

Jumlah ketersediaan panggung dengan permintaan kelompok teater pada saat maraknya perpindahan secara massif penduduk desa ke kota, membuat para seniman lokal Jakarta memiliki kesempatan yang tidak lagi banyak seperti sebelumnya. Keadaan tersebut menyebabkan gubernur melanjutkan pembangunan sejumlah pusat kesenian yang bersifat lokal dengan mendirikan gelanggang remaja.

\section{Sejarah Dewan Kesenian Jakarta}

Eksistensi TIM tentunya memerlukan lembaga yang melaksanakan pada tatanan operasional. Oleh karena itu, masyarakat seniman berinisiasi mendirikan kelembagaan yang diberikan kewenangan dan dapat bersinergi dengan kebijakan pemerintah. Lembaga tersebut dinamakan Dewan Kesenian Jakarta (DKJ) yang dikukuhkan oleh Gubernur DKI Jakarta pada tanggal 17 Juni 1969. Tugas dan fungsi DKJ adalah sebagai mitra gubernur DKI Jakarta untuk merumuskan kebijakan guna mendukung kegiatan dan pengembangan kehidupan kesenian di wilayah Provinsi DKI Jakarta. Anggota DKJ diangkat oleh Akademi Jakarta yang terdiri atas para budayawan dan cendekiawan dari seluruh Indonesia.

Sejalan dengan maksud pendirian TIM, DKJ menjadi keterwakilan para seniman dalam menumbuhkan kebudayaan yang lahir dari pemikiran anak bangsa dengan landasan kebebasan berpikir dan berpolemik. DKJ juga menjadi tiang penyangga para seniman dalam mengutarakan opini tanpa campur tangan kekuatan dan kekuasaan politik (Ikranegara, 1999).

Sepak terjang DKJ diawali dengan tujuh formatur dengan penetapan kebijakan berupa tugas lembaga antara lain: 1) untuk memberi contoh (model) dari manifestasimanifestasi kesenian terbaik yang dihasilkan oleh para seniman Indonesia dalam segala bidang kesenian yang ditemui di Indonesia (jadi termasuk daerah), dan 2) berusaha dengan segala macam cara untuk membina apresiasi masyarakat terhadap hasil-hasil kesenian yang bermutu. Dengan demikian, 
dapat mengalihkan perhatian orang banyak dari tontonan-tontonan dan pertunjukan yang diadakan berdasarkan selera burukbaik yang datang dari dalam dan luar negeri dengan jalan memberikan suatu "tandingan" dan menghindarkan diri dari penggunaan "kekuasaan melarang" yang umumnya amat merugikan perkembangan kebudayaan.

Kebijakan tersebut melahirkan sejumlah prosedur menampung aspirasi kesenian secara lahir dan batin yang terdapat di kalangan seniman. Adapun kebijakan tersebut memiliki misi tersendiri, yakni untuk pembentukan selera seni tinggi dengan pengharapan kemunculan ekspresi-ekspresi seni baru (Hauser, 2011) dan dapat diakui dalam konstruksi kesenian dunia.

Pemilihan anggota DKJ kini dilakukan secara terbuka, melalui pembentukan tim pemilihan yang terdiri dari beberapa ahli dan pengamat seni, selain anggota Akademi Jakarta. Nama-nama calon diajukan dari berbagai kalangan masyarakat ataupun kelompok seni. Masa kepengurusaan DKJ sebanyak tiga tahun dengan menjalankan sejumlah program tahunan yang terbagi atas sejumlah komite, antara lain komite film, komite musik, komite sastra, komite seni rupa, komite tari, dan komite teater. Melalui komite teater inilah muncul program tahunan yang dikenal dengan FTJ.

\section{FTJ: Kurun Waktu Tahun 1972-2000}

FTJ digagaskan oleh Wahyu Sihombing dengan tujuan menggiatkan pertumbuhan teater Jakarta dan mengisi panggung pertunjukan di Taman Ismail Marzuki (Sumardjo, 1997). Saat itu dinamakan Festival Teater Remaja Jakarta. Gagasan FTJ sebagai kegiatan rutin beriringan dengan tahun pendirian sejumlah gelanggang di lima wilayah kota adminsitrasi Jakarta. Dengan demikian, pementasan kelompok teater di Taman Ismail Marzuki merupakan prestise bagi kalangan seniman.

FTJ itu sendiri merupakan rangkaian proses produksi pertunjukan sejumlah ka- langan seniman. Diawali dengan sayembara naskah pertunjukan. Naskah yang terpilih menjadi materi pertunjukan yang harus disajikan kelompok teater. Kemudian dilakukan eliminasi terhadap interpretasi pemanggungan dari naskah terpilih oleh kelompok teater pada tingkatan wilayah yang diselenggarakan di tiap gelanggang di lima wilayah kota administrasi Jakarta. Hasil pengeliminasian selanjutnya dikontestasikan di TIM.

Proses FTJ yang diawali dari sayembara naskah memang berdampak pada bertambahnya literasi sastra. Hal itu dibuktikan dengan jumlah bank naskah yang semakin bertambah secara kuantitas tiap tahunnya. Namun, tentu saja dalam tiap hal positif selalu diikuti hal negatif, yakni kelompok-kelompok teater cenderung menunggu hasil pemenang lomba naskah agar dapat dianalisis supaya dapat disajikan dengan pemanggungan yang baik. Alhasil sejumlah kelompok teater seperti kehilangan warna sejati dari kelompoknya.

Proses FTJ dengan menggunakan naskah pemenang lomba terpaksa diubah, yakni dengan meniadakan keharusan mementaskan naskah pemenang lomba pada tahun 1987. Hal tersebut tentu mendatangkan keuntungan bagi sejumlah kelompok seniman yang menjunjung tinggi idealisme pementasan yang diyakininya. Kemunculan ini ditandai dengan pementasanpementasan eksperimen teater, seperti Teater SAE, Teater Kubur, Bandar Teater Jakarta, Teater Gelanggang Jakarta Timur, Teater Aquilla, dan masih banyak lainnya.

Bagi kelompok yang dinyatakan pemenang dalam FTJ, tentu saja akan mendapatkan sejumlah hadiah yang menarik, baik secara material maupun nonmaterial. Hak material tentu saja berupa adanya uang pembinaan yang dapat dimanfaatkan untuk memenuhi kebutuhan sehari-hari pegiat seni teater pada kelompok tersebut. Adapun secara nonmaterial adalah hak akses untuk melakukan pentas (hak tampil) di TIM. Tentu saja hak tampil itu adalah kesempatan untuk disaksikan oleh lebih banyak penonton yang memungkinkan untuk mendatangkan 
sejumlah uang, baik dari sponsor maupun dari penjualan tiket penonton. Selain itu, bagi kelompok teater yang telah memenangkan festival teater sebanyak tiga kali, akan mendapat predikat senior.

Legitimasi senior merupakan capaian puncak dan sebuah kebanggaan tersendiri. Sebagai teater senior yang sudah dilegitimasi oleh dewan juri yang terdiri dari tokoh-tokoh teater nasional, mendapatkan keistimewaan, didaulat sebagai teater yang mapan, mampu berdiri sendiri, dan berhak mengadakan pementasan di Taman Ismail Marzuki, sejajar dengan kelompok-kelompok teater profesional lainnya secara periodik.

\section{FTJ: Kurun Waktu Tahun 2000-2017}

Selama penyelenggaraannya, FTJ tidaklah lepas dari pro dan kontra yang mengkritisi, baik proses maupun hasil yang dicapai. Tidaklah asing apabila dalam kritikan tersebut bersifat konstruktif dan destruktif. Inisiasi perubahan FTJ pada kurun waktu tahun 2000 ini diawali pada pernyataan pengamat budaya, Noorca Masardi dan Radhar Panca Dahana, pada FTJ ke-21 tahun 1994. Masardi dan Dahana menyarankan agar FTJ dibubarkan atau diubah dengan program lain. Dahana menegaskan bahwa FTJ semestinya telah memasuki usia kedewasaan untuk memberi ruang kemungkinan artistik keteateran di ibukota (Dahana, 2001).

Ruang gerak informasi pada tahun 1994 memang sangat dibatasi, mengingat tahun itu suara seniman masih dibungkam oleh kekuasaan politik. Namun, perubahan susunan pemerintahan terjadi seiring dengan pendewasaan diri yang dilakukan oleh FTJ. Pada tahun 2000, seiring dengan penghapusan Departemen Penerangan pada era pemerintahan Presiden Abdurrahman Wahid, memberikan peluang besar bagi para seniman untuk ikut mengubah konsep pendewasaan diri.

Konsep pendewasaan yang dilakukan DKJ pada Festival Teater Remaja Jakarta, yakni dengan menghilangkan kata remaja. Memang pada saat penyandangan kata remaja banyak aspirasi kelompok seniman yang dibatasi dalam memberikan kontribusi pemikiran dan konsep pembaruan. Menyembunyikan diri dalam pengistilahan remaja saat itu dinyatakan tepat sebab bagaimanapun sebelum tahun 2000 semua aspirasi dikategorikan sebagai ungkapan kegelisahan remaja yang dianggap kurang berarti.

Sesungguhnya, secara faktual, pelaku seni tidaklah sepenuhnya remaja lagi. Banyak di kalangan pelaku seni sudah jauh dari sebutan remaja. Kebebasan berpendapat yang ditandai dengan perubahan penghapusan Departemen Penerangan memberikan ruang keartistikan baru yang digambarkan Dahana. Dahana menambahkan bahwa festival semestinya tidak ditelikung oleh sistem atau kriteria penilaian yang ketat (Dahana, 2001). FTJ pada kurun waktu tahun 2000 hingga kini dikembalikan pada hakikat festival. Festival dalam FTJ dimaknai sebagai sebuah pesta yang bersifat komemorasi (peringatan) yang membedakan makna festival dari pemaknaan umum lainnya (Sunardi, 2005).

Pesta sebagai komemorasi yang hakikatnya dalam festival adalah mengambil objek keberhasilan manusia memberi nilai. Komemorasi dalam festival senantiasa terkait dengan lahirnya nilai baru dalam masyarakat. Visi dalam sebuah festival kesenian merupakan manifestasi dari budaya kritis. Pemahaman ini bersumber pada cara kita membaca kesenian dan hubungannya dengan berbagai isu sensitif yang sedang berlangsung dalam kehidupan publik. Budaya kritis akan membuat festival bukan hanya berarti karena "siapa yang akan tampil" dalam festival tersebut, melainkan karena festival tersebut juga bagian dari budaya kritis yang bertanggung jawab kepada publik, yaitu bagaimana festival tersebut membangun budaya pertunjukan sebagai membuka berlangsungnya "perang ikon" dan publik bisa membaca perang itu adalah positif untuk membaca ulang keberadaan mereka di antara berbagai ikon publik yang 
sedang memainkan peranan penting dalam kehidupan bersama kita (Malna, 2005).

Budaya kritis itu sama pentingnya, yakni dalam menjawab bagaimana festival itu menempatkan dirinya dalam kondisi publik yang dihadapinya. Sebuah festival tentu saja tidak harus menjadi ekspresi dari seni publik. Namun, bagaimana festival itu dikemas dan melibatkan berbagai unsur penting di masing-masing kota, akan membuat festival itu menjadi bagian dari ekspresi kota.

Kalau dicermati, selama digelarnya FTJ memberikan gambaran perjalanan kota Jakarta sebagai kota metropolitan dalam bingkai seni teater. Afrizal Malna menyatakan bahwa FTJ tak hanya berhenti sebagai "peristiwa kesenian" namun juga merupakan bagian dari dinamika kehidupan Kota Jakarta (Malna, 2005).

FTJ menjadi fenomena pertumbuhan Jakarta, sejalan dengan kepesatan laju perubahan fisik Kota Jakarta yang banyak menggusur ruang-ruang kreativitas remaja sebagai wahana penyalur energi kreatif. FTJ terus melaju menjaga keseimbangan peradaban Jakarta. Bisa dibayangkan bagaimana para generasi muda kehilangan lahan aktivitas penyaluran energi kreatifnya, berkompensasi pada aktivitas destruktif yang merusak masa depannya, menjurus pada penghancuran peradaban kota (Tyasawan, 2012).

FTJ telah membuktikan keterlibatan ratusan, bahkan ribuan generasi muda Jakarta dan sekitarnya menjadi tertantang untuk terus-menerus setiap tahun melakukan upaya kreatif dalam event kompetitif. Pada sisi inilah FTJ masih dibutuhkan dan terus-menerus dilaksanakan.

Visi dalam festival menjadi sangat penting. Tidak hanya karena visi inilah setiap kelompok kesenian mempertanyakan dirinya kembali lewat festival yang akan diikutinya, tetapi juga bagaimana masyarakat kota menjadi terlibat lewat festival berlangsung di kotanya. Festival kesenian tidak hanya berfungsi memberikan pertanggungjawaban ke publik atas perkembangan, fenomena, dan gelombang kesenian yang sedang berlangsung, tetapi juga bisa untuk membongkar situasi dekadensi ataupun keterasingan, tidak hanya yang dihadapi kesenian, dan juga yang dirasakan oleh warga kota. Sebuah festival kiranya juga harus inheren menguasai peta sosial kota sebagai tempat berlangsungnya festival hingga warga kota ikut memilikinya (Malna, 2005).

Melibatkan kota dalam festival sama dengan mengikutkan masyarakat ke dalam pembentukan proses kualitatif kehidupan publik, dan membawa kebijakan kota untuk mempertimbangkan kualitas ruang publik dalam tata kota yang mereka ciptakan. Bahwa festival tidak hanya sibuk dengan berbagai pertunjukan, tetapi juga penting untuk pembentukan budaya pertunjukan dan bagian dari pembentukan budaya kota.

Sebagai peristiwa kesenian, FTJ terus melakukan perubahan demi pencapaian puncak keunggulan kualitas artistik dan estetikanya. Oleh karena itu, pengelola FTJ, yaitu Komite Teater Dewan Kesenian Jakarta terus melakukan perubahan sistem dan mekanisme pelaksanaannya untuk memberi ruang kemungkinan bagi pencapaian kualitas maksimal.

Perubahannya bukan saja pada sistem tata pengaturan pelaksanaannya, melainkan dengan dicanangkannya tema-tema acara yang menjadi dasar pilihan bagi kelompokkelompok teater peserta FTJ. Seperti perhelatan ke-40 tahun 2012, FTJ mengambil tema "Membaca Aku Membaca Laku" dengan subtema "Membaca Tradisi".

Pembongkaran subtema "Membaca Tradisi" untuk memberi pemahaman yang lebih jelas dan nyata pada kelompok-kelompok teater (calon) peserta FTJ 2012. Untuk itu, Komite Teater Dewan Kesenian Jakarta bekerjasama dengan asosiasi perteateran di lima wilayah kota administrasi se-DKI Jakarta telah melakukan beberapa program, seperti diskusi dan workshop. Program yang mengawali rangkaian pelaksanaan FTJ 2012 mulai di tingkat wilayah (babak penyisihan) 
sampai ke tingkat provinsi (babak final) ini diharapkan menjadi semacam perangsang dan pengondisian kehidupan perteateran di Jakarta. Peserta FTJ harus berupaya membaca pada persoalan peningkatan kualitas tampilan estetik dan artistik di satu sisi, sementara pada sisi konten (tema cerita) pun menyentuh persoalan kehidupan manusia, khususnya masyarakat urban Jakarta (Tyasawan, 2012).

Jangkauan dari dua sisi inilah yang nantinya diharapkan mewujudkan pada 'teater yang hidup' dan mengembalikan teater sebagai hiburan yang mencerdaskan serta menjadikan teater sebagai kebutuhan masyarakat Jakarta. Fenomena FTJ ini telah melahirkan dan mengakomodasi ekspresi kelompok teater yang banyak berdiam dalam kultur urban kontemporer masyarakat Jakarta. Dua nama besar teater jebolan FTJ, yaitu Teater SAE dan Teater Kubur, telah membuktikan kehadirannya dalam perteateran modern dengan konsep dan idealisme pemanggungannya sesuai karakteristik urban kontemporer Jakarta.

\section{Penutup}

TIM sebagai sentra kesenian Jakarta bahkan Indonesia, pada masa-masa awal tentunya telah memberi warna bagi kalangan seniman teater. Kemunculan TIM sebagai bentuk perwujudan wadah aspirasi seniman dalam mengemukakan gagasan, pemikiran, dan karya-karya yang bersumber dari persoalan kehidupan. TIM sendiri merupakan wadah atas bukti terselenggaranya pendewasaan kesenimanan pegiat teater di Jakarta, khususnya, dan di Indonesia pada umumnya. Melalui acara tahunan FTJ yang mengikuti perjalanan kota Jakarta, berhasil melahirkan sejumlah kelompok teater yang memilik daya ungkap keartistikannya.

Pengelolaan FTJ bermula dari bersifat sentral dilaksanakan di TIM, kini mulai dilaksanakan adanya seleksi di tingkatan wilayah. Hal itu jelas membuktikan bahwa setiap tahunnya terdapat banyak kelompok teater yang lahir dan tumbuh kembang untuk membuktikan eksistensi kelompok kepada ajang FTJ dan tentunya berharap adanya pengakuan dari pengamat, pelaku, dan penikmat teater.

Tidaklah dapat dipungkiri bahwa FTJ telah menjadi alasan sejumlah kelompok teater untuk tetap hidup, meskipun alasan kelompok-kelompok tersebut didominasi oleh faktor dukungan ketermudahan pemerolehan finansial, baik dari sponsor maupun hadiah uang pembinaan yang diberikan DKJ sebagai bentuk apresiasi. Namun demikian, keberadaan para pegiat seni yang tetap konsisten dan mampu bertahan dari himpitan dan atau desakan kekuasan politik di periode awal patut diapresiasi. Kini menjadi mampu mengubah sistem pengelolaan pertunjukan dengan memanfaatkan momen yang terjadi pada perkembangan ekonomi, sosial, politik, dan budaya di Indonesia. FTJ pun dapat menjadi saksi perjalanan karya atas problematika yang ada di kota Jakarta dan Indonesia, pada umumnya.

\section{Kepustakaan}

Ahmadi, D. 2020. LEKRA : Setelah 50 Tahun*. Medium.https: / / medium.com / @ doniahmadi/lekra-setelah-50-tahuna035beb8efd

Dahana, R. P. 2001. Homo Theatricus. Yayasan Indonesiatera.

Hauser, A. 2011. The Sociology of Art. Routledge. Ikranegara. 1999. Teater Nasional Indonesia. In Teater Indonesia: Konsep Sejarah, Problema. Dewan Kesenian Jakarta.

Kevin, S., \& Huwae, S. 2019. Gedung Galeri Kesenian Di Menteng, Jakarta Pusat. Jurnal STUPA, 1(1), 327-331.

Malna, A. 2005. Festival sebagai Peristiwa Kota dalam sorak sorai Festival (Ed. Khusus). GONG Media Seni dan Pendidikan Seni.

Moleong, L. J. 2008. Metodologi Penelitian Kualitatif. Remaja Rosdakarya.

Probo, V. 2015. Suara Veteran Lekra Menguak Kebenaran. CNN Indonesia. https://www.cnnindonesia.com / 
hiburan/20150930202508-241-81966/ suara-veteran-lekra-menguak-kebenaran Stake, R. E. 2010. Qualitative Research: Studying How Things Work. Guilford.

Sumardjo, J. 1997. Perkembangan Teater Modern dan Sastra Drama Indonesia. STSI
Press.

Sunardi, S. 2005. Mencari Mania dalam Religi, Uang dan Seni dalam Sorak Sorai Festival (Ed. Khusus). GONG Media Seni dan Pendidikan Seni.

Tyasawan, M. 2012. Wawancara dengan Madin. 